\title{
Natalizumab adverse events are rare in patients with multiple sclerosis
}

\author{
Eventos adversos por natalizumabe são raros em pacientes com esclerose múltipla
}

Yára Dadalti Fragoso', Soniza Vieira Alves-Leon², Walter Oleschko Arruda³, Margarete de Jesus Carvalho', Elizabeth Regina Comini-Frota5, Éber Castro Corrêa $a^{6}$, Maria Lucia Brito Ferreira7, Paulo Diniz da Gama ${ }^{8}$, Sidney Gomes ${ }^{9}$, Marcus Vinicius Magno Gonçalves ${ }^{10}$, Damacio Ramón Kaimen-Maciel ${ }^{11}$, Maria Fernanda Mendes ${ }^{12}$, Rogerio Rizo Morales ${ }^{13}$, Andre Muniz' ${ }^{14}$, Pedro Rippel Salgado ${ }^{15}$, Heloisa Helena Ruocco ${ }^{16}$, Livia Brito Bezerra de Albuquerque7, Joseph Bruno Bidin Brooks ${ }^{1}$, Letícia Fêzer ${ }^{2}$, Sergio Georgetto ${ }^{11}$, Josiane Lopes ${ }^{11}$, Fabiola Rachid Malfetano², Isabella D’Andrea Meira², Celso Luis Silva Oliveira', Francisco Tomaz Meneses de Oliveira ${ }^{9}$, Fabiana Safanelli ${ }^{10}$, Massaco Satomi ${ }^{15}$

\begin{abstract}
Objective: To assess the prevalence and the profile of adverse events (AE) of natalizumab in patients with multiple sclerosis (MS). Methods: Data collection from neurologists attending to patients with MS at specialized units in Brazil. Results: Data from 103 patients attending the infusion centers of $16 \mathrm{MS}$ units in 9 Brazilian states were included in the study. The total number of infusions was 1,042. Seventy-nine patients (76.7\%) did not present any AE. Twenty-four patients (23.3\%) presented only mild AE. There were three major AE, including two deaths. These three occurrences, although not necessarily being drug-related, must be taken into consideration. Conclusion: The profile of AEs for natalizumab shows that $97 \%$ of patients have none or only mild AE. However, still due to safety worries, the use of this medication should be restricted to MS units under the care of specialized neurologists.
\end{abstract}

Key words: multiple sclerosis, natalizumab, adverse events, antibodies, monoclonal.

\section{RESUMO}

Objetivo: Avaliar a prevalência e o perfil dos eventos adversos (EA) por natalizumabe em pacientes com esclerose múltipla (EM). Métodos: Coleta de dados fornecidos por neurologistas de unidades especializadas em EM no Brasil. Resultados: No estudo, foram incluídos dados de 103 pacientes em tratamento em centros de infusão de 16 unidades de EM em 9 estados brasileiros. 0 número total de infusões foi 1.042. Setenta e nove pacientes (76,7\%) não apresentaram nenhum EA. Vinte e quatro pacientes (23,3\%) apresentaram apenas EA leves. Foram relatados três importantes EA, incluindo duas mortes. Embora não necessariamente ligadas à droga, estas EA devem ser levadas em consideração. Conclusão: 0 perfil de EA para natalizumabe mostrou que em $97 \%$ dos pacientes não houve EA ou houve apenas EA leves. No entanto, dadas as preocupações com segurança da droga, o uso deste medicamento deve continuar restrito às unidades de EM sob os cuidados de neurologistas especializados.

Palavras-Chave: esclerose múltipla, natalizumabe, eventos adversos, anticorpos monoclonais.

\footnotetext{
${ }^{1}$ Universidade Metropolitana de Santos (UNIMES), Santos SP, Brazil;

${ }^{2}$ Universidade Federal do Rio de Janeiro (UFRJ), Rio de Janeiro RJ, Brazil;

${ }^{3}$ Universidade Federal do Paraná (UFPR), Curitiba PR, Brazil;

${ }^{4}$ Faculdade de Medicina do ABC (FMABC), Santo André SP, Brazil;

${ }^{5}$ Universidade Federal de Minas Gerais (UFMG), Belo Horizonte MG, Brazil;

${ }^{6}$ CLINEN, Neurologia e Endocrionologia, Brasília DF, Brazil;

${ }^{7}$ Hospital da Restauração, Recife PE, Brazil;

${ }^{8}$ Pontifícia Universidade Católica de São Paulo (PUC-SP), Sorocaba SP, Brazil;

${ }^{9}$ Hospital Beneficência Portuguesa de São Paulo; Hospital Paulistano, São Paulo SP, Brazil;

${ }^{10}$ Universidade da Região de Joinville (UNIVILLE), Joinville SC, Brazil;

${ }^{11}$ Universidade Estadual de Londrina (UEL), Londrina PR, Brazil;

${ }^{12}$ Faculdade de Ciências Médicas da Santa Casa de São Paulo (FCMSCSP), São Paulo SP, Brazil;

${ }^{13}$ Universidade Federal de Uberlândia (UFU), Uberlândia MG, Brazil;

${ }^{14}$ Hospital São Rafael de Salvador, Salvador BA, Brazil;

${ }^{15}$ Universidade Federal de Mato Grosso do Sul (UFMS), Campo Grande MS, Brazil,

${ }^{16}$ Centro de Atendimento de Esclerose Múltipla, Jundiaí SP, Brazil.
}

Correspondence: Yara Dadalti Fragoso; Departamento de Neurologia da UNIMES; Rua da Constituição 374;11015-470 Santos SP - Brasil; E-mail:yara@bsnet.com.br Conflict of interest: There is no conflict of interest to declare.

Received 22 August 2012; Received in final form 25 September 2012; Accepted 02 October 2012. 
Natalizumab (Tysabri ${ }^{\square}$, Biogen Idec) is a monoclonal antibody that inhibits leukocyte migration across the bloodbrain barrier through selective inhibition of $\alpha-4$ integrin. Natalizumab effectively reduces inflammation in the central nervous system ${ }^{1}$ and has been approved worldwide for treating relapsing-remitting multiple sclerosis (RRMS) ${ }^{2}$. This drug is used in intravenous infusions and should only be used by skilled neurologists in multiple sclerosis (MS) centers under monitoring programs ${ }^{1}$.

In Brazil, as in other countries, natalizumab has been recommended for use when both glatiramer acetate and interferon beta have failed to control the relapses and severe disease activity in $\mathrm{RRMS}^{3,4}$. Guidelines from the Brazilian Academy of Neurology now indicate that natalizumab can be used as first line therapy or after failure of one immunomodulatory drug 5 . Safety concerns relating to the drug have limited the number of neurologists using natalizumab in many countries and, as a rule, only a small group of Brazilian neurologists have a few cases under their care.

Although the main safety issue with natalizumab is the development of progressive multifocal leukoencephalopathy $(\mathrm{PML})^{6}$, other aspects of the drug also deserve attention. Reactions during infusions, which have been reported to occur in up to $10 \%$ of all patients ${ }^{7}$, require the specific care that only knowledgeable physicians will be able to provide.

It is imperative to widen the Brazilian experience with the use of natalizumab, including data on the profile of adverse events of this drug. Our population and health systems are unique and, therefore, we cannot simply absorb data from North America, Europe and Asia. The aim of the present study was to investigate adverse events to natalizumab and their medical management in Brazil. The study was conducted by an independent task force.

\section{METHODS}

Ethical approval was obtained for each institution according to their specific requirements.

Neurologists and health care personnel working at specialized MS centers in Brazil were invited to contribute to this study by sending details of infusion reactions in natalizumab-treated MS cases under their care. The study was independent of all pharmaceutical companies, academia, private or governmental institutions. Patients who had received immunosuppressive drugs in the past were only included in the natalizumab protocol if at least six months had elapsed since the end of immunosuppressive drug administration, in accordance with current Brazilian and international recommendations ${ }^{3,4}$.

Retrospective data from medical records were collected and forwarded to a central database. In order to maintain confidentiality, all information was given using only the gender and age of the patients. The total number of infusions and the occurrence and type of adverse event in each infusion were noted. Short term adverse events were considered to be those occurring during the infusion and up to 24 hours after that. Mild, moderate and/or severe adverse events were registered in detail. Since these records came from highly specific infusion centers in accredited hospitals, the information had been carefully noted by the medical staff. Management of adverse events by the medical team was registered.

The results are essentially descriptive and, therefore, no statistical analysis was required. In order to assess whether the presence of adverse events was correlated to gender or age of the patients, a simple Pearson correlation test was performed. Otherwise, results are simply the expression of mean values and standard deviations, as well as descriptive data.

\section{RESULTS}

Twenty-three neurologists and three health care professionals directly linked to the infusion centers of 16 MS units in 9 Brazilian states participated in the study. The database consisted of 103 patients who presented very aggressive RRMS without proper response and with inadequate disease control with the use of immunomodulatory drugs.

The group of MS patients consisted of 71 women and 32 men with an average age of $30.7 \pm 11.2$ years (range: 17 to 62 years). All patients had clinical disease activity (relapses) and new lesions seen on magnetic resonance imaging, despite the use of immunomodulatory drugs (interferon beta and glatiramer acetate). The most severe cases were bedridden (three patients). Prior to the first infusion, all patients had been carefully screened for systemic infections, including tuberculosis.

The total number of infusions was 1,042, corresponding to an average of 10.1 infusions per patient (range: 1 to 41 ).

Seventy-nine patients $(76.7 \%)$ did not present any adverse event during or after any of their 807 infusions. Twentyfour patients (23.3\%) presented only mild adverse events, all of them within 24 hours after the infusion. The most frequent event was skin reaction during and immediately after the infusion in seven cases (6.8\%). This reaction was characterized by general redness and/or pruritus and most doctors resorted to dexamethasone or prednisone to relieve these symptoms. There were no cases requiring withdrawal from natalizumab treatment, although four patients presented more than one episode of this allergy-like reaction.

Another mild side effect was headache during or immediately after the infusion, affecting six patients (5.8\%). Generalized pain and/or muscle spasms, nausea, vomiting, hiccups, dizziness, high blood pressure, asthenia, fatigue, worsen of spasticity, respiratory infection, urinary infection, visual blurring, low fever and paresthesia were much less 
frequently reported and were typical of the two days following the infusion. Most side effects were observed in the first three infusions, but some patients presented the same symptoms in all or most of them. In general, the relationship between these side effects and the drug was considered to be "probable" or "very likely" by the doctors in charge of the cases. None of these adverse events required the patient to be withdrawn from natalizumab treatment. There were no correlations between age $(\mathrm{p}=0.36)$ and gender $(\mathrm{p}=0.57)$ and the presence of adverse events.

In summary, the most frequent adverse events observed during and immediately after the infusion of natalizumab were general redness and/or pruritus and headache. During the 48 hours following the infusion, mild and reversible unspecific symptoms were reported by 20 patients (19.4\%).

When followed by a longer period of time, three cases presented more serious complications. One patient presented a moderate adverse event, characterized by fungal infection in the skin of the torso. The patient was bedridden and, although no culture was performed, the infection subsided with local use of antifungal creams. This infection recurred in every infusion between the third and the ninth doses, when natalizumab was then suspended. The infection did not reappear and the relationship with the drug was considered to be "very likely".

Two patients presented severe adverse events resulting in death. In both cases the fatal outcome occurred after the first infusion of natalizumab and these were not bedridden patients. The first case was a female patient aged 48 years who presented a relapse on the week subsequent to the infusion and, during this relapse, had cardiac infarction and arrest. The relationship of the drug to the patient's death was unclear, but cannot be ruled out. After careful investigation, there was no evidence of infections in the central nervous system to explain the neurological symptoms and, therefore, the adverse event was considered to be a relapse rather than encephalitis. The second patient who died was a female aged 37 years, who presented a relapse 48 hours after the infusion. She then presented a massive respiratory infection, acute respiratory failure and septicemia, culminating with death 60 days after the infusion. Again, the relationship between the fatal outcome and the drug could not be confirmed, but could not be ruled out either. Like in the first case, the adverse event was again considered to be a relapse rather than encephalitis after all the investigations.

Except for the cases of moderate and severe adverse events, one case intending to become pregnant and for two cases of JC virus with previous use of immunosuppressive drugs, all other 97 patients continue to receive the drug. Although the aim of this study was not assessing efficacy of the drug, all neurologists using natalizumab reported that they were satisfied with the results in controlling aggressive RRMS. This group of authors agrees that natalizumab is an important therapeutic option for MS and must remain in the health system reimbursement. Any further comments on drug efficacy would be unwise since the study design did not contemplate this assessment.

\section{DISCUSSION}

Natalizumab is a very specific monoclonal antibody for treating MS. As is the case with all monoclonal antibodies, the very good efficacy profile of these drugs shares space with important safety concerns ${ }^{8}$. Although the prevalence of moderate and severe adverse events is typically low $^{8}$, it must be kept in mind that treatment with all monoclonal antibodies may be related to opportunistic infections, development of tumors and autoimmune phenomena, allergic and anaphylactic reactions, cytokine release syndrome and, possibly, heart failure ${ }^{8,9}$. With natalizumab in particular, the main concern is opportunistic infection by the JC virus, which gives rise to a condition of severe PML ${ }^{1,6,10}$. Some countries have specific pharmacovigilance protocols for reporting on PML and other side effects with natalizumab ${ }^{3}$, but Brazil is not one of them. In Brazil, adverse events are reported directly to the national agency for pharmacovigilance (ANVISA). While the clinical characteristics and incidence of PML are clear in the mind of all neurologists prescribing natalizumab, other side effects, such as short term infusion-related adverse events, are not often discussed. The present study reporting on the profile of adverse events for natalizumab in Brazil is the first independent and multicenter national work on this subject.

Skin reactions to natalizumab have previously been reported $^{1,7,8}$ and are usually managed by injections of corticosteroids. They do not usually require suspension of the drug treatment, unless the reaction is triggered by antibody-mediated reactions ${ }^{7,11,12}$. In our series of patients, natalizumab treatment persisted and the doctors medicated the patients presenting skin reaction, with dexamethasone or prednisone prior to all other infusions, with good results. Headache, mild infections and fatigue which were found in our study, are among the common mild adverse events reported in clinical trials ${ }^{13}$. None of these or other mild and limited side effects culminated with drug withdrawal in our series of patients.

Although adverse events occurring after 48 hours of the infusion were not the objective of this study, the profile of moderate and severe adverse events observed here was relatively uncommon and particularly worrying. Severe dermatological fungal infection has previously been described ${ }^{14}$, but no further reports have followed that initial one. The fatal cases observed in our study were particularly different from those reported in the literature, where death was mainly related to later development of PML. The two female adult patients with severe adverse events in our study both presented their complications in the very first infusion, which led them 
to death. One patient died of a heart attack and the other had severe lung infection, respiratory distress and septicemia. Congestive heart failure has been suggested (but not confirmed) as a possible side effect of natalizumab ${ }^{15}$, while recurrent pericarditis has been reported once ${ }^{16}$. To clarify whether deaths observed in these patients are a fatality or the results of uncommon adverse events, is beyond the scope of the present study. Patients undergoing natalizumab treatment are often severe cases of MS, and may be more prone to complications due to their frailty. However, as the relationship between natalizumab and these deaths cannot be excluded, the authors recommend additional attention to myocardial infarction and severe pneumonia during the use of natalizumab.

One important limitation of the present report is the immortal time bias ${ }^{17,18}$. Observational studies are subject to this factor, which can be clearly understood if it is considered that patients who have undergone one or two infusions without adverse events are not comparable to those who had already undergone 30 or more infusions and presented adverse reactions. The explanation is that the patient with few infusions and no side effects may still be subject to more infusions and develop symptoms that have not appeared at the time of this cross-sectional evaluation. Patients with more infusions may have a better survival profile, meaning that they may have overcome problems that patients with fewer infusions will still have to face in their treatment. This type of bias could explain why the two fatal cases occurred after the first drug infusion. It is difficult to overcome this bias in a study like this one, and awareness of this possibility must be raised. However, in addition to other observational studies, cross sectional observations such as this one will help to compensate for other potential biases ${ }^{19}$.

In summary, natalizumab is a good option for the treatment of MS and has a satisfactory efficacy profile with regard to many aspects of the disease $e^{1,10,20}$. However, the adverse events relating to patients using this drug are still being learned. The more restricted recommendations on the use of natalizumab ${ }^{3,4}$ are giving space to more flexible indications of the drug ${ }^{5}$. Results from the present study showed that $97 \%$ of our patients had no or only mild adverse effects to the infusions, not requiring treatment interruption. Although this fact is very reassuring, it is important to highlight that there were cases of moderate and severe adverse events after the second day of the infusion. However small and with dubious relation to the drug, the number of deaths is worrying and should be part of a specific database accessible to all neurologists in the country. These moderate and severe adverse events must be regularly reported to the pharmacovigilance agencies and made known to all neurologists in Brazil. As a word of caution, it would be advisable that only skilled neurologists in MS centers under surveillance programs should use natalizumab. Exactly the same recommendation is found in the Cochrane database review ${ }^{1}$.

In conclusion, a very large number of patients in this study presented no adverse events on natalizumab. The moderate and severe side effects observed in our patients reported here are a word of warning. Endorsing the recommendations of the Cochrane review, the authors agree that natalizumab should only be used by experienced neurologists who must report adverse events to the national pharmacovigilance agency ANVISA.

\section{References}

1. Pucci E, Giuliani G, Solari A, et al. Natalizumab for relapsing remitting multiple sclerosis. Cochrane Database Syst Rev 2011;10:CD007621.

2. Lublin FD, Reingold SC. Defining the clinical course of multiple sclerosis: results of an international survey. National Multiple Sclerosis Society (USA) Advisory Committee on Clinical Trials of New Agents in Multiple Sclerosis. Neurology 1996;46:907-911.

3. Finkelsztejn A, Gabbai AA, Fragoso YD, et al. Latin American algorithm for treatment of relapsing-remitting multiple sclerosis using diseasemodifying agents. Arq Neuropsiquiatr 2012;70:799-806.

4. Ministério da Saúde do Brasil, Imprensa Nacional, Brasília, DF. n 184 - Diário Oficial da União 24 Sep 10 - p. 679 - section 1 number 493, 23rd Sept 2010.

5. Melges LDD, Alvarenga MP, Pimentel MLV. Anticorpos monoclonais em esclerose múltipla. In: Machado S, et al. Recomendações esclerose múltipla. São Paulo, Omnifarma, 2012:53-59.

6. Bloomgren G, Richman S, Hotermans C, et al. Risk of natalizumabassociated progressive multifocal leukoencephalopathy. N Engl J Med 2012;366:1870-1880.

7. Hellwig K, Schimrigk S, Fischer M, et al. Allergic and nonallergic delayed infusion reactions during natalizumab therapy. Arch Neurol 2008;65:656-658.
8. Casanova Estruch B. Safety profile and practical considerations of monoclonal antibody treatment. Neurologia 2011 [Epub ahead of print] PMID 2159627.

9. Singh JA, Wells GA, Christensen R, et al. Adverse effects of biologics: a network meta-analysis and Cochrane overview. Cochrane Database Syst Rev 2011;2:CD008794.

10. Goodin DS, Cohen BA, O'Connor P, Kappos L, Stevens JC. Assessment: the use of natalizumab (Tysabri) for the treatment of multiple sclerosis (an evidence-based review): report of the Therapeutics and Technology Assessment Subcommittee of the American Academy of Neurology. Neurology 2008;71:766-773.

11. Namey M, Halper J, O'leary S, Beavin J, Bishop C. Best practices in multiple sclerosis: infusion reactions versus hypersensitivity associated with biologic therapies. J Infus Nurs 2010;33:98-111.

12. Barbaud A, Granel F, Waton J, Poreaux C. How to manage hypersensitivity reactions to biological agents? Eur J Dermatol 2011;21:667-674.

13. Rudick RA, Panzara MA. Natalizumab for the treatment of relapsing multiple sclerosis. Biologics 2008;2:189-199.

14. Gutwinski S, Erbe S, Münch C, Janke O, Müller U, Haas J. Severe cutaneous Candida infection during natalizumab therapy in multiple sclerosis. Neurology 2010;74:512-523. 
15. Stallmach A, Hagel S, Bruns T. Adverse effects of biologics used for treating IBD. Best Pract Res Clin Gastroenterol 2010;24:167-182.

16. Cohen M, Rocher F, Brunschwig C, Lebrun C. Recurrent pericarditis due to natalizumab treatment. Neurology 2009;72:1616-1617.

17. Sylvestre MP, Huszti E, Hanley JA. Do OSCAR winners live longer than less successful peers? A reanalysis of the evidence. Ann Intern Med 2006;145:36-363
18. Suissa S. Immortal time bias in pharmaco-epidemiology. Am J Epidemiol 2008;167:492-499.

19. Maclure M, Fireman B, Nelson JC, et al. When should case-only designs be used for safety monitoring of medical products? Pharmacoepidemiol Drug Saf 2012;21(Suppl 1):S50-S61.

20. Rudick RA, Miller D, Hass S, et al. Health-related quality of life in multiple sclerosis: effects of natalizumab. Ann Neurol 2007;62:335-346. 